to link clinical neuropsychiatry with quantitative neurobiology. This does not mean that drugs are the only answer to treatment. Targeted psychological treatments such as cognitive-behavioural therapy can use the brain's capacity for neuroplasticity to remedy or restore communications within neurocircuits in some psychiatric conditions.

Insel, T. R. \& Bruce, N. C. (2015) Brain disorders? Precisely. Science, 348, 499. doi: $10.1126 /$ science.aab2358

\section{Brain grey matter and blood groups}

W e know of some drugs such as lithium increasing brain grey matter but did you know that our own blood group, ABO type, has a major role to play? There is evidence that people with blood group $\mathrm{AB}$ have a higher incidence of cognitive deficits. This led researchers to examine possible differences in grey matter volumes between people with blood group $\mathrm{O}$ and those with other blood groups; none of the participants had cognitive impairment or neurodegeneration. They found that those with blood group $\mathrm{O}$ had larger volumes of grey matter in the posterior ventral portion of the cerebellum (areas responsible for sensorimotor information) as well as in the temporal and limbic regions, including the left hippocampus. These findings point to a neuroprotective role for the blood group $\mathrm{O}$ alleles and suggest that blood group types are relevant to the development of the nervous system as well as the ageing process.

De Marco, M. \& Vepperi, A. (2015) 'O' blood type is associated with larger grey-matter volumes in the cerebellum. Brain Research Bulletin, 116, 1-6. doi: 10.1016/j.brainresbull.2015.05.005

\section{Mental illness and creativity - is there a link?}

T

he connections between creativity and mental

illness were made as far back as ancient Greece and Aristotle, and it has fascinated people for centuries. The authors of this study tried to examine this possible connection using scientific methods. They investigated whether common genetic variants that affect risk for schizophrenia and bipolar disorder also underlie advantageous cognitive traits. They used polygenic scores or cumulative genetic profiles from across the genome and generated separate polygenic risk scores for schizophrenia and bipolar disorder on nonIcelandic populations. They then tested the ability of polygenic scores to predict the corresponding disease in 86292 people in Iceland and looked for an association between these polygenic scores and creativity. Creativity was defined as individuals belonging to national artistic societies of actors, dancers, musicians, visual artists and writers. Both the schizophrenia and bipolar disorder polygenic risk scores were associated with creativity. The authors conclude that creativity may increase the risk of psychiatric disorder. Nevertheless, in the absence of other important pathogenic factors it is unlikely that our talented artists or writers will experience mental illness.

Power, R. A., et al (2015) Polygenic scores for schizophrenia and bipolar disorder predict creativity. Nature Neuroscience (online). doi: $10.1038 / \mathrm{nn} .4040$

\section{Stranded and drowned in the Mediterranean - who cares?}

lmost daily we hear of boats full of people $\mathbf{1}_{\text {capsizing on the way to Europe. Italy and }}$ Greece are constantly on the alert, fishing out desperate people from overcrowded boats reaching their waters. About 1500 people are thought to have perished in the Mediterranean between January and May 2015. The survivors face an uncertain future. European citizens are facing the biggest test of their humanity and sense of responsibility to the rest of the world. Many European countries need to reflect on their colonial past and more recent involvement in Africa and the Middle East and ponder over how they became so affluent and powerful. With power comes responsibility. Unfortunately, globalisation has failed to decrease the gap between the rich and the poor in the world. It seems to serve the economic interests of the powerful, with no real benefit to those who are weak. Is this a matter for doctors to consider? Pandora welcomes readers' views.

\section{A beautiful mind}

T is with great sadness that Pandora reports the 1 death of the famous mathematician John Forbes Nash. His remarkable research has been applied to a number of important areas, including macroeconomics, arms control and political science. He shared the Nobel Prize in Economics in 1994 and was on his way from a ceremony in Oslo, where he had been awarded the 2015 Abel Prize, accompanied by his wife, Alicia de Larde Nash, when their taxi crashed, killing them both, on 23 May. John Nash became more widely known by the film A Beautiful Mind, which was based on his life and which portrayed him battling with delusions and hallucinations. However, psychiatric treatment enabled him to continue his high-calibre work despite his illness (schizophrenia). His life shows both doctors and patients that mental illness, even one as serious as schizophrenia, can be controlled (he was treated with powerful antipsychotic drugs) and its presence should not be an end to one's aspirations.

\section{BJPsych International's blog}

http://www.bjpinternationalblog.org

Now features:

Reflection on MRCPsych examination in the UK Viviane Ngwompo

There is no mental health without caregivers Jens Peter Dam Eckardt Jensen

Child psychiatry in Iran Hadi Shaker Naeeni

Absence of humanities in China's training of psychiatrists

Jie Li, Maosheng Ran and Cecilia Lai-Wan Chan

My first 100 private outpatients in India - the experience of a psychiatrist trained in the UK Sundararajan Rajagopal

Opportunities to improve prison mental healthcare Annie Bartlett and Gillian McGauley 